\title{
Cuminaldehyde: A Potential Drug Candidate
}

\author{
*Mohamed Elsaed Ebada \\ Department of Pharmacology, National Organization for Drug Control and Research (NODCAR), Egypt
}

Submission: February 25, 2017; Published: March 08, 2017

*Corresponding author: Mohamed Elsaed Ebada, Department of Pharmacology, National Organization for Drug Control and Research (NODCAR), 51 Wezaret El-Zeraa Street, Agouza, Giza, Egypt, Tel: 002010 69637558; Email: drmohamedebada36@gmail.com

\begin{abstract}
Cuminaldehyde is one of major constituents identified in the essential oil of a number of commonly used spices such as green cumin (Cuminum Cyminum L.) which has been traditionally used for the treatment of dyspepsia, diarrhea, abdominal colic and Jaundice. Cumin essential oil has multiple pharmacological actions including antioxidant, antidiabetic, anti-inflammatory, antibacterial and anticancer effects. Therefore, a great deal of attention has been given to investigate the role of cuminaldehyde in mediating cumin's multiple therapeutic benefits. This short review highlights the most significant recently reported findings which unravel the extent to which cuminaldehyde contributes to the therapeutic effects of its producing herbs. Apart from its non-medical effects as natural bio-fumigant, cuminaldehyde is a promising potential drug candidate against various diseases.
\end{abstract}

Keywords: Cuminaldehyde; Anticancer; Antidiabetic; Anti-inflammatory; Neuroprotection; Antimicrobial; Fumigant

\section{Introduction}

Cuminaldehyde (Figure 1), an oxidized aldehyde monoterpene, is a major essential oil component [1-3] in green cumin seeds (Cuminum cyminum Linn, Family Apiaceae) which is a widely used spice cultivated natively in Egypt and later spread to various geographical locations mainly Asia, North Africa and Southern Europe, Mexico and Chile with India and Iran as the major producing countries [4-6]. Cuminaldehyde has also been determined in high amount in other commonly used spices such as true Cinnamon tree [7] and Black zira [8]. Cuminum cyminum is traditionally used to ease abdominal colic [9], treat dyspepsia [10,11], diarrhoea and jaundice [12]. It also has antioxidant [6,13] antibacterial [2] and antifungal effects [14]. Anticonvulsant activity of cumin oil was also reported [15]. In this review, recent findings suggesting different promising medical effects of cuminaldehyde will be discussed in the light of established therapeutic effects reported for the whole Cuminum cyminum essential oil.

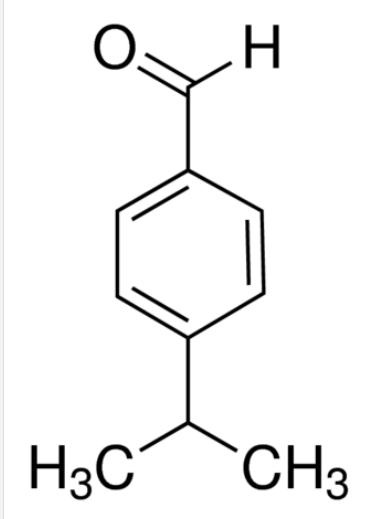

Figure 1: Chemical structure of cuminaldehyde (4-Isopropylbenzaldehyde). 


\section{Medical Effects (Figure 2)}

\section{Antidiabetic effects of cuminaldehyde}

It has been reported that cuminum cyminum has antidiabetic effects [16] as it was effective in reducing elevated blood glucose levels, enhancing insulin secretion and exerting antioxidant protective effects on insulin secreting $\beta$ cells in diabetic rats compared to clinically used oral hypoglycaemic agent glibenclamide $[12,17]$. Likewise, patients diagnosed with type II diabetes exhibited improved control over hyperglycaemia and enhanced insulin sensitivity after 8 week treatment with 50 or $100 \mathrm{mg} / \mathrm{kg} /$ day green cumin [18]. Indeed, cuminaldehyde has been found to contribute to the antidiabetic effects of cumin. Earlier, cuminaldehyde demonstrated significant but relatively lower inhibitory effects on aldose reductase and alpha glucosidase than an orally approved antidiabetic drug acarbose [19]. Later, Patil et al. [20] 2013 showed that cuminaldehyde had glucose dependent insulinotropic effects in diabetic rats, an effect which was found to be mediated through blocking ATP sensitive potassium channels and increasing intracellular calcium concentration in cultured rat pancreatic cells. Moreover, cuminaldehyde protected pancreatic $\beta$ cells against cytotoxicity induced by streptozotocin [20].

\section{Anticancer effects of cuminaldehyde}

Over the past decade, a growing body of evidence has shed lights on the antineoplastic activity of Cuminaldehyde. Nitoda et al. [21] demonstrated inhibitory effects of cuminaldehyde at low concentrations on melanin synthesis by mouse melanoma cell line but not by human melanoma cells, although cuminaldehyde became rather cytotoxic at higher concentrations for both cancer cell lines. Recent studies have provided insight into the mechanisms of cuminaldehyde cytotoxicity. First, cuminaldehyde was found to trigger pro-apoptotic proteins such as caspase 3 and 9 , alter the integrity of mitochondria and inhibit the malignancyincreased activity of DNA integrity-conserving enzymes including topoisomerase I and II, thereby enhancing apoptosis and growth inhibition of human colorectal adenocarcinoma cells [7]. Such anticancer effects of cuminaldehyde were validated in a mouse model of colorectal cancer, demonstrating reduced tumour size elicited by cuminaldehyde-enhanced apoptosis [7]. Another study using NCI-H520 Cells featuring human lung squamous cell carcinoma exhibited similar results with broad stimulatory effects on the apoptosis pathway manifested with increased expression of pro-apoptic bax and bac and decreased expression of bcl-XL and bcl-2, apoptosis suppressing factors [22]. In the previous study, cuminaldehyde induced apoptosis was also evidenced by the increased release of mitochondrial cytochrome c as well as elevated activity of lactate dehydrogenase in the culture medium [22]. Also, cuminaldehyde increased lysosomal vacuolation and acidic compartment volume [7,22]. Despite its promising antitumor effects, cuminaldehyde is considered a safe drug candidate as it showed no cytotoxicity on PC12 cells using MTT cytotoxicity assay [23].

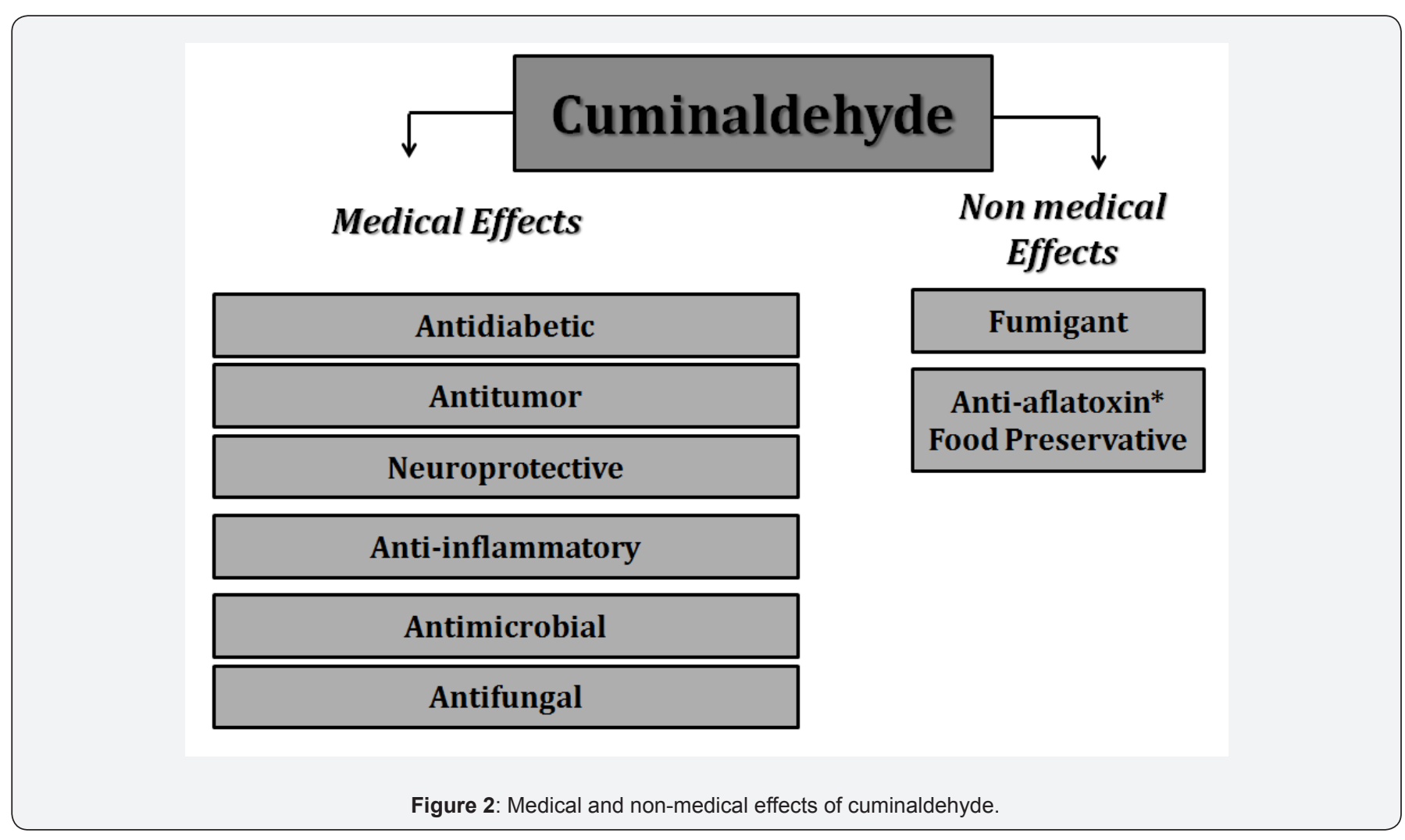

*Effects have been determined for Cuminum cyminum essential oil which contained cuminaldehyde as a major constituent. 


\section{Cuminaldehyde possesses neuroprotective effects}

Cuminum cyminum has been shown to act centrally. For example, cumin extract was found to have nootropic effects and to attenuate scopolamine-induced amnesia in rats [24]. Cumin essential oil attenuated morphine-induced conditioned place preference [25] and this effect was suggested to involve inhibition of the central nitric oxide synthesis [26]. On the other hand, cuminaldehyde has been recently found to exert protective effects against neurodegenerative diseases in particular Parkinson's disease. This was evidenced by its long lasting suppressing effects on the fibrillation of alpha synuclein, the pathogenesis hallmark of Parkinson's disease, compared to baicalein, a standard alpha synuclein fibrillation suppressor [23]. Additional investigation suggested that cuminaldehyde impaired $\beta$-structural assembly of alpha synuclein fibrils, thereby inhibiting its fibrillation [23]. On the contrary, inhibitory effects of cuminaldehyde on alpha synuclein fibrillation was weakened by essential oil of Myrtus communis [27], indicating that essential oils from natural sources are not always beneficial.

\section{Potential anti-inflammatory effects of cuminaldehyde}

With regard to supressing inflammatory process, cumin essential oil was found to be effective in reducing different features of lipopolysaccharide induced inflammation in cultured macrophage cells including decreased mRNA expression of proinflammatory cytokines such as interleukin 1 and 6, inducible nitric oxide synthase and cyclooxygenase type II [3]. Cumin oil also reduced protein levels of nuclear factor-kappa B, phosphorylated extracellular signal regulated kinase and phosphorylated c-Jun $\mathrm{N}$-terminal Kinase [3]. In this study by Wei et al. [3], it should be pointed out that cuminaldehyde accounted for $48.77 \%$ of the whole content of cumin essential oil, suggesting potential anti-inflammatory effects of cuminaldehyde. Cuminaldehyde itself competitively inhibited the activity of 15-lipoxygenase, an enzyme involved in the production of inflammatory mediators such as leukotrienes, using lipoxygenase inhibition assay [28].

\section{Antimicrobial and antifungal activity}

As stated earlier, cumin essential oil was reported to have antibacterial and antifungal effects [2], antimalarial [13], and it inhibited the growth of aflatoxin-producing fungi such as Aspergillus flavus [14], proposing that cuminaldehyde could partially mediate such effects as it constituted a considerable portion of the whole cumin essential oil. An Iranian clinical study on female patients suffering from recurrent vulvovaginal candidiasis, cumin oil demonstrated marked antifungal activity against candida albicans strains identified in vaginal samples isolated from infected women using the broth microdilution method [29]. Cuminaldehyde was one major component of cumin essential oil (18.8\%) used in the former study, indicating that it could contribute to the reported fungicidal effects of cumin essential oil.

\section{Non-medical effects: Fumigant applications (Figure 2)}

Apart from its promising medical effects, cuminaldehyde showed profound antifungal activity against a soil-borne Fusarium oxysporum [8], supporting its powerful fumigant use against phytopathogenic fungi. Cuminaldehyde was also found to selectively inhibit the acetylcholinesterase in insects and pests feeding on and damaging plants and therefore it could be safely used as an excellent natural bio-fumigant [30-32].

\section{Funding sources}

This research did not receive any specific grant from funding agencies in the public, commercial, or not-for-profit sectors.

\section{References}

1. Rihawy MS, Bakraji EH, Odeh A (2014) PIXE and GC-MS investigation for the determination of the chemical composition of Syrian Cuminum cyminum L. Appl Radiat Isot 86:118-125.

2. Hajlaoui H, Mighri H, Noumi E, Snoussi M, Trabelsi N, et al. (2010) Chemical composition and biological activities of Tunisian Cuminum cyminum L. essential oil: a high effectiveness against Vibrio spp. strains. Food Chem Toxicol 48(8-9): 2186-2192.

3. Wei J, Zhang X, Bi Y, Miao R, Zhang Z, et al. (2015) Anti-Inflammatory Effects of Cumin Essential Oil by Blocking JNK, ERK, and NF-kappa B Signaling Pathways in LPS-Stimulated RAW 264.7 Cells. Evid Based Complement Altern Med 2015: 474509.

4. Anshul Bansal, Vaibhav Bansal, Rajeshwar Singh (2014) Cumin: A spice or a drug? World Journal of Pharmaceutical Sciences 2(5): 507-515.

5. Mnif S, Aifa S (2015) Cumin (Cuminum cyminum L.) from traditional uses to potential biomedical applications. Chem Biodivers 12(5): 733742 .

6. Allahghadri T, Rasooli I, Owlia P, Nadooshan MJ, Ghazanfari T, et al. (2010) Antimicrobial property, antioxidant capacity, and cytotoxicity of essential oil from cumin produced in Iran. J Food Sci 75(2): H54-H61.

7. Tsai KD, Liu YH, Chen TW, Yang SM, Wong HY, et al. (2016) Cuminaldehyde from Cinnamomum verum Induces Cell Death through Targeting Topoisomerase 1 and 2 in Human Colorectal Adenocarcinoma COLO 205 Cells. Nutrients 8(6): 318.

8. Sekine T, Sugano M, Majid A, Fujii Y (2007) Antifungal effects of volatile compounds from black zira (Bunium persicum) and other spices and herbs. J Chem Ecol 33(11): 2123-2132.

9. Kumar D, Ganguly K, Hegde H V, Patil PA, Kholkute SD (2015) Spasmolytic effect of traditional herbal formulation on guinea pig ileum. J Ayurveda Integr Med 6(3): 194-197.

10. Nostro A, Cellini L, Di Bartolomeo S, Di Campli E, Grande R, et al. (2005) Antibacterial effect of plant extracts against Helicobacter pylori. Phytother Res 19(3): 198-202.

11. Vador N, Jagtap AG, Damle A (2012) Vulnerability of Gastric Mucosa in Diabetic Rats, Its Pathogenesis and Amelioration by Cuminum cyminum. Indian J Pharm Sci 74(5): 387-396.

12. Dhandapani S, Subramanian VR, Rajagopal S, Namasivayam N(2002) Hypolipidemic effect of Cuminum cyminum $L$. on alloxan-induced diabetic rats. Pharmacol Res 46(3): 251-255.

13.Zheljazkov VD, Gawde A, Cantrell CL, Astatkie T, Schlegel V(2015) Distillation Time as Tool for Improved Antimalarial Activity and 
Differential Oil Composition of Cumin Seed Oil. PLoS One 10(12): e0144120.

14. Kedia A, Prakash B, Mishra PK, Dubey NK (2014) Antifungal and antiaflatoxigenic properties of Cuminum cyminum (L.) seed essential oil and its efficacy as a preservative in stored commodities. Int J Food Microbiol 168-169: 1-7.

15. Janahmadi M, Niazi F, Danyali S, Kamalinejad M (2006) Effects of the fruit essential oil of Cuminum cyminum Linn. (Apiaceae) on pentylenetetrazol-induced epileptiform activity in F1 neurones of Helix aspersa. J Ethnopharmacol 104(1-2): 278-282.

16. Bi X, Lim J, Henry CJ (2016) Spices in the management of diabetes mellitus. Food Chem 217: 281-293.

17. Jagtap AG, Patil PB (2010) Antihyperglycemic activity and inhibition of advanced glycation end product formation by Cuminum cyminum in streptozotocin induced diabetic rats. Food Chem Toxicol 48(8-9): 2030-2036.

18. Sahar Jafari, Roghieh Sattari, Sa'id Ghavamzadeh (2016) Evaluation the effect of 50 and $100 \mathrm{mg}$ doses of Cuminum cyminum essential oil on glycemic indices, insulin resistance and serum inflammatory factors on patients with diabetes type II: A double-blind randomized placebocontrolled clinical trial. J Tradit Complement Medicine.

19. Lee HS (2005) Cuminaldehyde: Aldose Reductase and alphaGlucosidase Inhibitor Derived from Cuminum cyminum L. Seeds. J Agric Food Chem 53(7): 2446-2450.

20. Patil SB, Takalikar SS, Joglekar MM, Haldavnekar VS, Arvindekar AU (2013) Insulinotropic and beta-cell protective action of cuminaldehyde, cuminol and an inhibitor isolated from Cuminum cyminum in streptozotocin-induced diabetic rats. Br J Nutr 110(8): 1434-1443.

21. Nitoda T, Fan MD, Kubo I (2008) Effects of cuminaldehyde on melanoma cells. Phytother Res 22(6): 809-813.

22. Yang SM, Tsai KD, Wong HY, Liu YH, Chen TW, et al. (2016) Molecular Mechanism of Cinnamomum verum Component Cuminaldehyde Inhibits Cell Growth and Induces Cell Death in Human Lung Squamous Cell Carcinoma NCI-H520 Cells In Vitro and In Vivo. J Cancer 7(3): 251261.
23. Morshedi D, Aliakbari F, Tayaranian-Marvian A, Fassihi A, Pan-Montojo F, et al. (2015) Cuminaldehyde as the Major Component of Cuminum cyminum, a Natural Aldehyde with Inhibitory Effect on Alpha-Synuclein Fibrillation and Cytotoxicity. J Food Sci 80(10): H2336-H2345.

24. Koppula S, Choi DK (2011) Cuminum cyminum extract attenuates scopolamine-induced memory loss and stress-induced urinary biochemical changes in rats: a noninvasive biochemical approach. Pharm Biol 49(7): 702-708.

25. Khatibi A, Haghparast A, Shams J, Dianati E, Komaki A, et al. (2008) Effects of the fruit essential oil of Cuminum cyminum $L$. on the acquisition and expression of morphine-induced conditioned place preference in mice. Neurosci Lett 448(1): 94-98.

26. Kermani M, Azizi P, Haghparast A (2012) The role of nitric oxide in the effects of cumin (Cuminum Cyminum L.) fruit essential oil on the acquisition of morphine-induced conditioned place preference in adult male mice. Chin J Integr Med.

27. Morshedi D, Nasouti M (2016) Essential Oils May Lead alpha-Synuclein towards Toxic Fibrils Formation. Parkinsons Dis 2016: 6219249.

28. Tomy MJ, Dileep K V, Prasanth S, Preethidan DS, Sabu A, et al. (2014) Cuminaldehyde as a lipoxygenase inhibitor: in vitro and in silico validation. Appl Biochem Biotechnol 174(1): 388-397.

29. Minooeianhaghighi MH, Sepehrian L, Shokri H (2016) Antifungal effects of Lavandula binaludensis and Cuminum cyminum essential oils against Candida albicans strains isolated from patients with recurrent vulvovaginal candidiasis. J Mycol Med.

30. Abdelgaleil SA, Mohamed MI, Badawy ME, El-arami SA (2009) Fumigant and contact toxicities of monoterpenes to Sitophilus oryzae (L.) and Tribolium castaneum (Herbst) and their inhibitory effects on acetylcholinesterase activity. J Chem Ecol 35(5): 518-525.

31. Sung-Woong Kim, Jaesoon Kang, Il-Kwon Park (2013) Fumigant toxicity of Apiaceae essential oils and their constituents against Sitophilus oryzae and their acetylcholinesterase inhibitory activity. Journal of Asia-Pacific Entomology 16(4): 443-448.

32. Badawy ME, El-Arami SA, Abdelgaleil SA (2010) Acaricidal and quantitative structure activity relationship of monoterpenes against

\section{Your next submission with Juniper Publishers} will reach you the below assets

- Quality Editorial service

- Swift Peer Review

- Reprints availability

- E-prints Service

- Manuscript Podcast for convenient understanding

- Global attainment for your research

- Manuscript accessibility in different formats ( Pdf, E-pub, Full Text, Audio)

- Unceasing customer service

Track the below URL for one-step submission https://juniperpublishers.com/online-submission.php 